University of Nebraska - Lincoln

DigitalCommons@University of Nebraska - Lincoln

$4-22-2020$

\title{
Live Cattle Basis Due to Covid-19: Deviations and Convergence
}

Elliott James Dennis

University of Nebraska - Lincoln, elliott.dennis@unl.edu

Follow this and additional works at: https://digitalcommons.unl.edu/ageconfarmmgmt

Part of the Agribusiness Commons, Entrepreneurial and Small Business Operations Commons, Management Information Systems Commons, Other Business Commons, Other Economics Commons, and the Other Immunology and Infectious Disease Commons

Dennis, Elliott James, "Live Cattle Basis Due to Covid-19: Deviations and Convergence" (2020). Extension Farm and Ranch Management. 27.

https://digitalcommons.unl.edu/ageconfarmmgmt/27

This News Article is brought to you for free and open access by the Agricultural Economics Department at DigitalCommons@University of Nebraska - Lincoln. It has been accepted for inclusion in Extension Farm and Ranch Management by an authorized administrator of DigitalCommons@University of Nebraska - Lincoln. 


\title{
Live Cattle Basis Due to Covid-19: Deviations and Convergence
}

\author{
By Dr. Elliott Dennis
}

April 22, 2020

\begin{abstract}
A Fundamental Review on Basis
Basis is defined as the cash minus futures. Cash market reflects today's supply conditions and price. Futures market reflects upcoming supply and demand conditions. If it is anticipated that there will be a period of increasing supplies, futures prices will decline to reflect that information. Likewise, periods of time with expected decreasing supplies, future prices are expected to increase.
\end{abstract}

Since cash and futures prices can move simultaneously, basis will fluctuate through time. In periods where basis becomes more positive (i.e. basis is said to be strengthening/narrowing) it implies that cash prices are increasing more relative to futures. As basis becomes more negative (i.e. basis is said to be weakening/widening) it implies that cash prices are decreasing relative to futures. Basis can weaken or strengthen in periods of declining or rising futures and cash prices. Declining cash prices does not necessarily imply weakening basis. It is the relative relationship between cash and futures that determine basis.

Futures markets exist as an exchange or risk transfer between market participants. Cattle producers agree to deliver cattle to a given location, date, and specified price. Packers or meat wholesalers agree to purchase cattle under contract specifications. This contract for future delivery allows both parties to better predict output/input prices and thus profitability. The contract does not eliminate risk but rather allows the exchange of price risk for basis risk. Since basis is specific to a time a place, it must be predictable and reliable to allow the futures markets to be used as an effective risk management strategy.

The basis position provides some signal of the near future supply and demand conditions. If basis is negative the market is said to be a "normal market" implying no supply shortage. In order for producers to bring cattle to market, basis would need to increase. When basis is over, the market is said to be a "premium market" implying a supply shortage. Producers see the basis and have an incentive to deliver to the market thus decreasing basis.

\section{Why Convergence is Needed}

Since futures markets are designed for price discovery and risk management as the contract nears expiration, the futures and cash markets must converge on price There are three primary reasons why nonconvergence between futures and cash prices is problematic. First, convergence makes hedging an effective tool. Lack of convergence or variation in convergence causes basis risk and creates disincentives for producers to use the risk management tool. This disincentive is due to the hedger not being insulated from price risk due to random variation in basis. Second, convergence indicates equilibrium between supply and demand conditions. If convergence does not occur, then it may not accurately represent supply and demand conditions. Thus, the contract ceases to be useful to hedgers and trading will eventually disappear. 


\section{Physical Delivery on Cattle Forces Convergence}

Most futures contracts traded on the Chicago Mercantile Exchange (CME) are cash settled. In other words, no physical delivery takes place when a contract expires. One of the few exceptions is the Live Cattle contract. The primary purpose of delivery in this contract is to "force" convergence in the market at certain times of the year. Most deliveries are experienced in October, but few occur in summer months. Delivery does not need to constantly occur to force markets to converge. Often only the threat of delivery is sufficient.

Cattle delivery will only occur when cash is less than futures. In this case, after accounting for all the added costs of delivery, if cattle are delivered it simultaneous reduces futures and increases cash prices, as there are fewer cattle in the cash market and the entity receiving delivery must liquidate their position in the futures market. Delivery will continue to take place as long as basis strengthens/narrows to the point where the costs and risks of delivery are no longer covered.

When cash is greater than futures, there is no incentive for delivery. Producers have an incentive to not deliver since they would receive a lower price from futures than they could in the cash market. Hedges will be lifted by buying offsetting contracts in the futures once cattle are sold in the cash market during the delivery month. This buying will pressure futures prices to rise. This price increase will continue as long as people wanting to take delivery maintain their positions in the futures market. If they maintain their position in the market until the contract expires, then they will effectively guarantee delivery of cattle. However, once again there will reach a point where the difference between cash and futures prices is no longer profitable to accept delivery. In both cases, as long as there are no major structural issues in the delivery process (i.e. not enough delivery locations etc.) the incentive and threat of delivery causes futures and cash prices to converge.

\section{Current Convergence Situation for Various States and Regions}

Figure 1 plots basis for Nebraska, Texas, Kansas, and the five-market region from weeks using the April 2020 Live Cattle contract (LCJ20). It shows how basis has moved through time as the LCJ20 contract has moved towards expiration. There is no apparent differences in basis across geographical regions. Since early mid-February, basis has strengthened across all regions to approximately $+\$ 15$. Given our previous discussion on what basis reveals about supply and demand, a positive basis would indicate a lack of supply of fed cattle needed to be supplied to the market. This pattern is particularly odd given the situation with COVID-19 where packing plant closures have significantly reducing the demand for fed cattle.

\section{Historical Performance of Convergence in Nebraska Fed Cattle}

Although this year is something we have never seen before, recent historical basis patterns may be able to provide some information on what basis is likely to do in the next week or so before expiration. I use historical basis patterns in Nebraska (NE) since all states have similar basis patterns. Figure 2 plots weekly historical basis patterns for NE for the LCJ contract in 2017, 2019, 2020, and an average over the past five years 2015-2019. Once again it shows how basis has changed as the LCJ contract nears expiration. Convergence occurs when the cash and futures converge to the same price as contract expires. A perfect example of this is 2019. The contract varied through time but converged as weeks to expiration decreased. On average over the past five years, has strengthened till approximately the middle to end of February followed by a decrease in basis. The cash and futures prices have done a relatively good job at converging as the contract expires. The marketing year 2017 is plotted to show some comparison to our unusual 2020 year. Seven to eight weeks out, basis was relatively strgng, $+\$ 13$. Then at the end of March 2017 the contract 
began to converge although did not fully converge with cash prices finishing approximately $+\$ 3$ to futures. This year appears to be following a similar pattern, although the pattern is much higher and more delayed.

\section{Cash Meet Futures or Does Futures Meet Cash?}

There are very serious concerns that cash and futures contracts will not likely converge in the next week or so. In both 2017 and 2020 cash prices were higher than futures heading into the month of April. As previously discussed, in 2017 cash and futures prices did not converge. There are three ways prices can converge in 2020: 1) cash constant and futures rise, 2) cash declines and futures constant, and 3) cash declines and futures rise. Using data from 2015-2019, I show historical price movements of basis and cash as the LCJ contract nears expiration.

Table 1 panel (a) displays convergence as a percent change $(\% \Delta)$ in either futures or cash price using varying weeks to expiration. A positive number indicates that the price at expiration was higher than various weeks prior. For example, the first row (\% $\Delta$ in Cash 8 weeks prior) is 0.88 indicating that when LCJ15 expired cash price was $0.88 \%$ higher than the cash price 8 weeks prior to expiration (i.e. first week in March). The different columns indicate different April live cattle futures contracts in the year which they expire (i.e. LCJ15 is the Live Cattle future contract that expired April 2015). The percent change in cash and futures prices varies considerably across years reflecting supply and demand conditions unique to each year. In other words, it varies considerably whether cash or futures prices rises or decreases significantly in select weeks prior to contract expiration. Averaging over five years ('15-'19) indicates that cash prices tend to slightly fall $(0.02 \%-0.76 \%$ price change $)$ as contract expiration nears. Futures prices tend to rise slightly $(0.67 \%-0.97 \%)$ as contract expires. The most movement in prices happens 4 weeks prior to contract expiration.

Perhaps a more intuitive way to capture changes in price movements is through the share in price movements. This captures the total price movement in both cash and futures and shows whether cash or futures moved more as the LCJ contract expired. For example, in the first row of 8 weeks prior to contract expiration, cash accounted for $18 \%$ of the price movements and futures accounted for $87 \%$. On average, cash explains the most price changes one month prior to contract expiration. Almost all the price movement one week prior $(97 \%)$ comes from futures contract but there is significant variation year to year. Comparing 2017 to 2020, it is most likely that both futures and cash prices are going to need to move in order for the LCJ20 contract to settle. However, if the nonconvergence issues that occurred in 2017 occur in 2020 cash is most likely to settle higher than futures. 


\section{Tables and Figures}

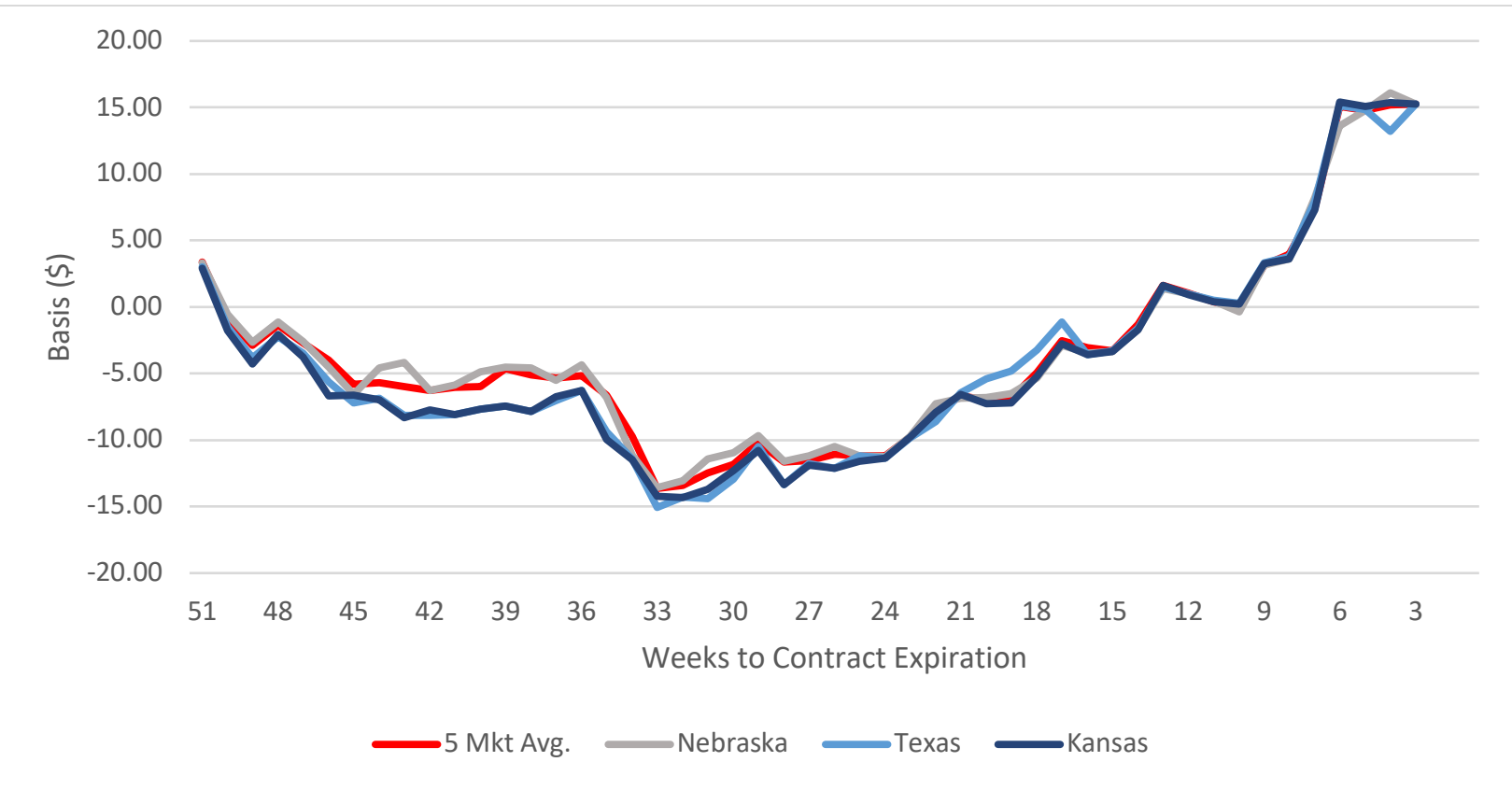

Figure 1. LCJ20 Convergence for Select Fed Cattle States and Regions

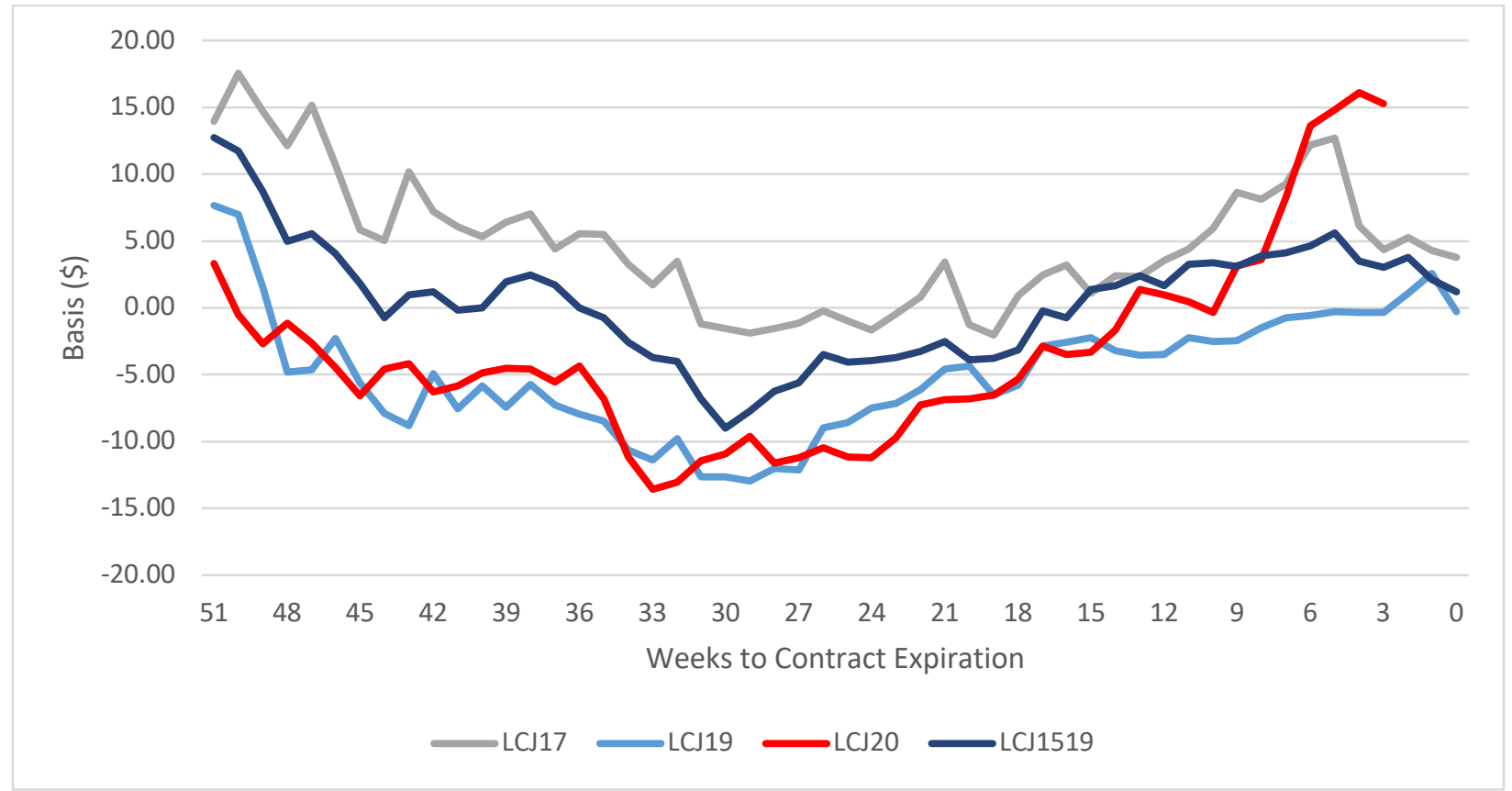

Figure 2. Historical Nebraska Fed Cattle Convergence on April Futures Contract 
Table 1. Historical Change in Cash and Futures Prices as LCJ Contract Expires, Various Weeks to Expiration

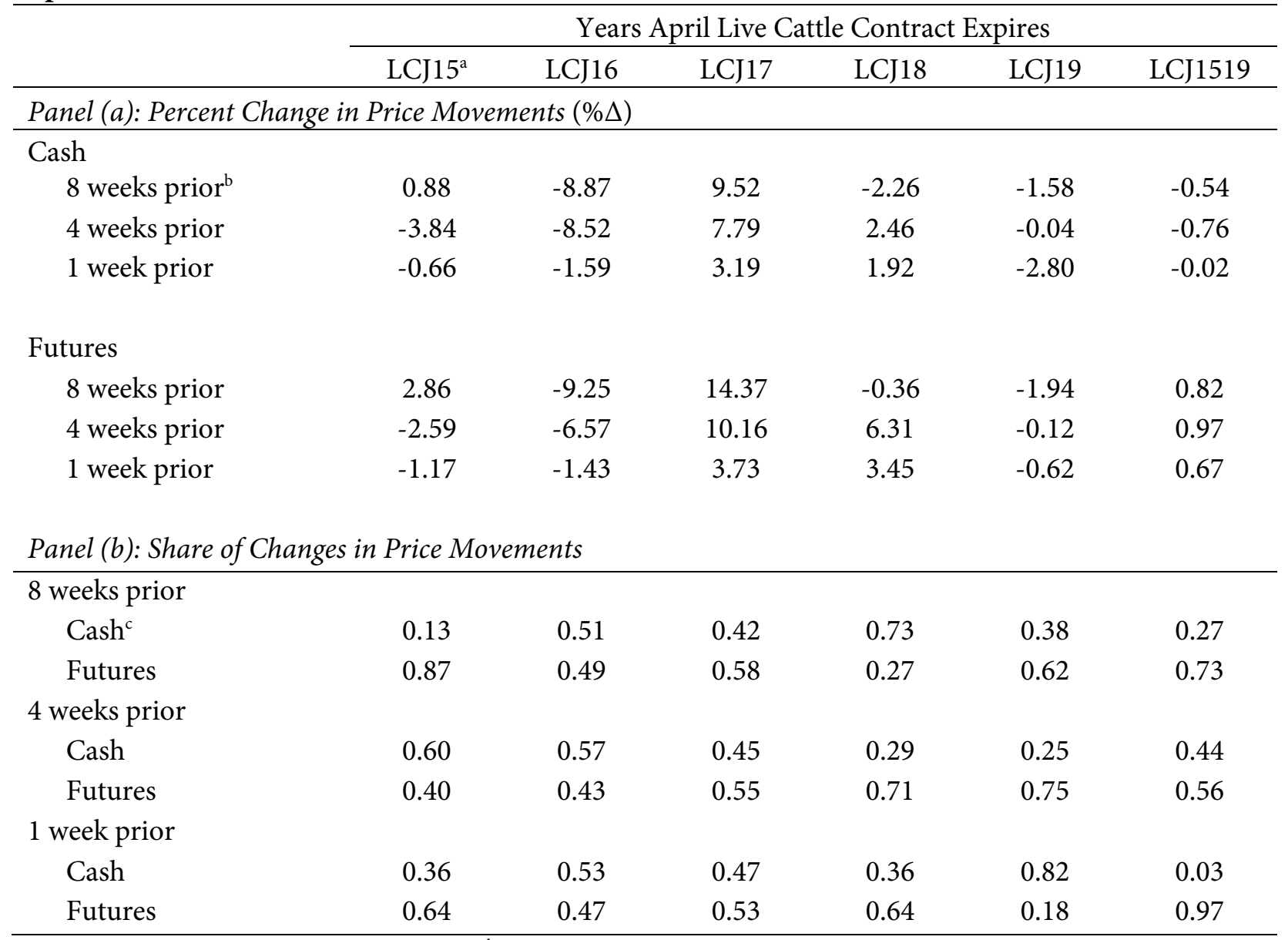

Notes: ${ }^{a} 2015$ April Live Cattle contract; ${ }^{b}$ Percent change in Nebraska Fed Cattle cash price between closing week and cash price eight weeks prior [( $0 \mathrm{wk}$. prior $-8 \mathrm{wk}$. prior $) / 8 \mathrm{wk}$. prior $\mathrm{x} 100]$; ${ }^{\mathrm{c}}$ Share of total price movements prior to expiration abs(Cash 8 wk. prior - Cash 0 wk. prior)

[abs(Cash 8 wk. prior - Cash 0 wk. prior) + abs(Futures 8 wk. prior - Futures 0 wk. prior) $]$.

Elliott Dennis is an assistant professor and livestock marketing economist in the Department of Agricultural Economics. 